\title{
Characterization of the residues in glass bottle from the Song Dynasty by GC-QTOF-the earliest archaeological recorded ambergris at present
}

\section{Li Ding ( $\nabla$ dingli@chnmuseum.cn )}

National Museum of China https://orcid.org/0000-0002-4810-2036

\section{Yanru Ma}

National Museum of China

\section{Yonghai Fu}

National Center for Archaeology

Qin Yang

National Museum of China

Jiajia Wu

Agilent Technologies(China)Co.,Ltd

We Xie

qing hua da xue: Tsinghua University

Research article

Keywords: GC QTOF, ambergris, incense, the Grand Bao'en Temple

Posted Date: December 22nd, 2020

DOI: https://doi.org/10.21203/rs.3.rs-130628/v1

License: (c) (i) This work is licensed under a Creative Commons Attribution 4.0 International License.

Read Full License 


\title{
Characterization of the residues in glass bottle from the Song Dynasty by GC-
}

\author{
QTOF---the earliest archaeological recorded ambergris at present \\ Li Ding ${ }^{1}$, Yanru Ma ${ }^{1}$, Yonghai $\mathrm{Fu}^{2}$, Qin Yang ${ }^{1}$, Jiajia $\mathrm{Wu}^{3}, \mathrm{We} \mathrm{Xie}^{4}$ \\ 1 National Museum of China, No.16 East Chang'an Avenue, Dongcheng District, Beijing \\ 100006, P. R. China \\ 2 National Center for Archaeology, Building 4, Yard 1, South Baosheng Road, Haidian \\ District, Beijing, Beijing 100192, P. R. China \\ 3 Agilent Technology, 3 Wangjing Bei Lu, Chaoyang District, Beijing, 100102, PR, China \\ 4 Tsinghua University, Beijing,100084, P. R. China
}

\begin{abstract}
The organic residues in a glass bottle excavated from the Grand Baoen Temple site in the Song Dynasty, in Jiangsu Province, were studied in this paper. The Fourier transform infrared (FT-IR) spectroscopy, Gas chromatography-quadrupole mass spectrometry (GC-QMS) and Gas chromatography quadrupole time-of-flight mass spectrometry (GC-QTOF-MS) were applied to characterize the material. By comparing the 7 modern collected ambergris reference samples, the residue in the bottle was identified as ambergris. The biomarker molecule ambrein was detected in the residues via solvent vent mode and the co-eluent of interferent was checked using secondary Q-TOF mode. Furthermore, the occurrence of ambergris in the underground palace demonstrates the well-developed overseas incense trade and the solemn Buddhist culture of using incense in the Song Dynasty.
\end{abstract}

Keywords GC-QTOF, ambergris, incense, the Grand Bao'en Temple

\section{Introduction}

The Great Bao'en Temple(大报恩寺)historical site was discovered in 2008 and is located on the south bank of external Qinhuai River in Nanjing, China (Fig.1). The Great Bao'en Temple used to be Changgan Temple, which was built in the Northern Song Dynasty (960-1127), with a long history of Buddhist heritage. It is the deepest underground stupa palace found in China. There are more than 13,000 artifacts unearthed in the palace, including gold, silver, bronze, crystal, glass and agate. ${ }^{[1,2]}$ The cultural relics unearthed in the underground palace are mainly distributed in three layers, the first layer is a stone casket, the second is an iron casket and the third is the tower of king Ashoka. Among them, a calabash glassware numbered DG1:42 was unearthed in the iron casket. When it was unearthed, it was well preserved as a whole, with a cloth plugged into the mouth. Inside the glass, there is a white waxy substance and a note bearing the words in Chinese. Archaeologists speculate that it was a very valuable incense ambergris. During the Song Dynasty, the importation of exotic incense reached its peak. It is a very reasonable conjecture to take ambergris as a tribute. The ancients' understanding of ambergris, has been widely existing in literature. Many influential works mentioning ambergris were by physicians. The Persian Rhazes gave the medicinal properties of Ambergris. ${ }^{[3]}$ In China, 
Representative Answers from the Region beyond the Mountains (Lingwai Daida) is a 12th century geographical treatise written by Zhou Qufei. It provides knowledge of distant lands in China during the Song dynasty, and the distant land includes the overseas states as far away as Africa and southern Spain. It described the ambergris in very detail with the property and usage. In addition to literature documentation, there are several modern collected samples of ambergris, which are archived with exactly collected year. Some of them are collected in the 19th century, most are obtained in recent 10 years. One famous example is a boulder of ambergris weighing $155 \mathrm{~kg}$ taken from a male sperm whale on board Fl. F. Southern Harvester at 55 59'S, 0302'E on 21 November 1947. ${ }^{[4]}$ However, archaeological findings about the ambergris are seldom reported. The Quanzhou ship was a trade ship from the Song Dynasty and was discovered in 1973. ${ }^{[5]}$ The cargo of the ship was incense wood and also small amounts of valuable ambergris, which were judged by archaeologists via empirical observation. ${ }^{[6]}$ Its chemical component was not verified by scientific analysis. As a rare material, ambergris can only be used by people with very high social status in ancient times, and its quantity was scarce. At the same time, as an organic material, ambergris is very unlikely to be preserved after a long time burying storage. Therefore, it needs a sensitive detection method. Gas chromatography-mass spectrometry (GC-MS) is widely used to separate and detect organic residues: Laura Blanco-Zubiaguirre analysis the wine markers in archeological potteries at ultratrace levels, ${ }^{[7]}$ Shuya Wei analysis the lamp oil residue from Haihunhou Tomb.

${ }^{\left[{ }^{83}\right.}$ Joanna Kałużna-Czaplińska reviews the analytical procedures of different organic residue (lipids, fatty acids and other biomarkers) based on the GC-MS. However, traditional quadrupole instruments provide limited sensitivity in the scan mode. High resolution gas chromatography quadrupole time-of-flight mass spectrometry (GC-QTOF MS) proves more suitable for the identification of trace amount of compounds in complex samples. ${ }^{[9-1]}$ It not only provides full spectra with high sensitivity in first-stage mode (TOF spectra) but also acquires product ions spectrum with accurate masses in second-stage mode (Q-TOF spectra) to eliminate co-eluting signals and improve qualification accuracy. ${ }^{[12-14]}$

In order to investigate whether the incense is ambergris or not, 7 modern ambergris were collected to build a reference database. The composition features of ambergris extract were studied via FT-IR and GC-QMS. The results were applied to preliminary screening of an archaeological sample. Further high-resolution GC-QTOF verified that the existence of ambrein in the sample excavated in the glass bottles. This incense sample is the earliest evidence of ambergris used by people with solid scientific evidence so far, and it is an important historical object of incense usage in the Song Dynasty in addition to a physical evidence of ancient religion spiritual life.

\section{Experimental}

\section{Fourier transform infrared (FT-IR) spectrometry}

The FT-IR analyses were carried out on a Nicolet IS50 advanced Fourier transform infrared spectrometer (American Thermo Fisher Scientific Cooperation). The spectra were collected over the $4000-500 \mathrm{~cm}^{-1}$ using attenuated total reflectance (ATR) for the measurements.

\section{Gas chromatography-quadrupole mass spectrometry (GC-QMS)}


GC-QMS analysis was performed using an Agilent 7890A (Agilent Technologies, Santa Clara, CA, USA) gas chromatograph interfaced to an Agilent 5975C quadrupole mass spectrometer, separation was achieved using a DB-5MS $30 \mathrm{~m} \times 0.25 \mathrm{~mm} \times 0.25 \mu \mathrm{m}$. The GC was run in splitless mode with an inlet temperature of $230^{\circ} \mathrm{C}$, MS interface temperature $280{ }^{\circ} \mathrm{C}$. Ultrahigh purity helium was used as carrier gas with a constant linear flow of $1.0 \mathrm{ml} \mathrm{min}{ }^{-1}$. The GC oven temperature was programmed with a ramp of $10^{\circ} \mathrm{C} / \mathrm{min}$ from $40^{\circ} \mathrm{C}$ to $300{ }^{\circ} \mathrm{C}$ held for $10 \mathrm{~min}$. The MS was run in scan mode from 33-700 amu with the source and quadrupole set at 230 and $150{ }^{\circ} \mathrm{C}$, respectively. The MS was operated in electron impact (El) positive ion mode $(70 \mathrm{eV})$. The solvent delay was $10 \mathrm{~min}$.

\section{Gas chromatography-quadrupole time-of-flight mass spectrometry (GC-QTOF-MS)}

Agilent 7250 high resolution GC-QTOF MS platform equipped with a multimode inlet (MMI) was employed for the identification of trace amount components. The separation was achieved using a DB-5MS $30 \mathrm{~m} \times 0.25 \mathrm{~mm} \times 1.0 \mu \mathrm{m}$. The inlet temperature and MS interface temperature were programmed and $280^{\circ} \mathrm{C}$ respectively. For the archaeological sample, the injection volume was $8 \mu \mathrm{L}$. The $\mathrm{MMI}$ was operated in solvent vent mode and related parameters were as follows: $100{ }^{\circ} \mathrm{C}(0.07 \mathrm{~min})$, and ramp at $650^{\circ} \mathrm{C} / \mathrm{min}$ to $300{ }^{\circ} \mathrm{C}$; vent flow was $100 \mathrm{~mL} / \mathrm{min}$ at pressure of $5 \mathrm{psi}$ for $0.07 \mathrm{~min}$. For reference samples, the injection volume was injected $1 \mu \mathrm{L}$ and the $\mathrm{MMI}$ was used in splitless mode at $280^{\circ} \mathrm{C}$. Ultra-high purity helium was used as carrier gas with a constant linear flow of $1.0 \mathrm{ml} \mathrm{min}^{-1}$. The $\mathrm{GC}$ oven temperature was held at $50^{\circ} \mathrm{C}$ for $1 \mathrm{~min}$, then programmed with a ramp of $25^{\circ} \mathrm{C} / \mathrm{min}$ from $50^{\circ} \mathrm{C}$ to $100^{\circ} \mathrm{C}$ and $10^{\circ} \mathrm{C} / \mathrm{min}$ from $100^{\circ} \mathrm{C}$ to $300^{\circ} \mathrm{C}$, held for $30 \mathrm{~min}$. The MS ran in first order TOF mode or second order Q-TOF mode. Mass scanning range from 33-650 amu.

\section{Residue Extraction}

$10 \mathrm{mg}$ sample was taken from specimens of ambergris using an alcohol rinsed scalpel blade and spatula and digested by sonication ( $2 \times 5 \mathrm{~min}$ ) in $1 \mathrm{ml}$ Toluene. The dispersion was centrifuged at $5000 \mathrm{rpm}$. The supernatant liquid was taken for further analysis.

\section{Reference Materials}

The ambergris samples were purchased from the two independent ambergris merchants. The one supplied the ambergris from the Middle East (Sample 1,2,3). The other resold the ambergris from the Hainan province, where local people collected ambergris near the coast (Sample 4,5,6,7).

\section{Archaeological Materials}

The archaeological incense sample was taken from the glass bottle numbered DG1:42, which was found in the Grand Bao'en Temple (Figure.2). 


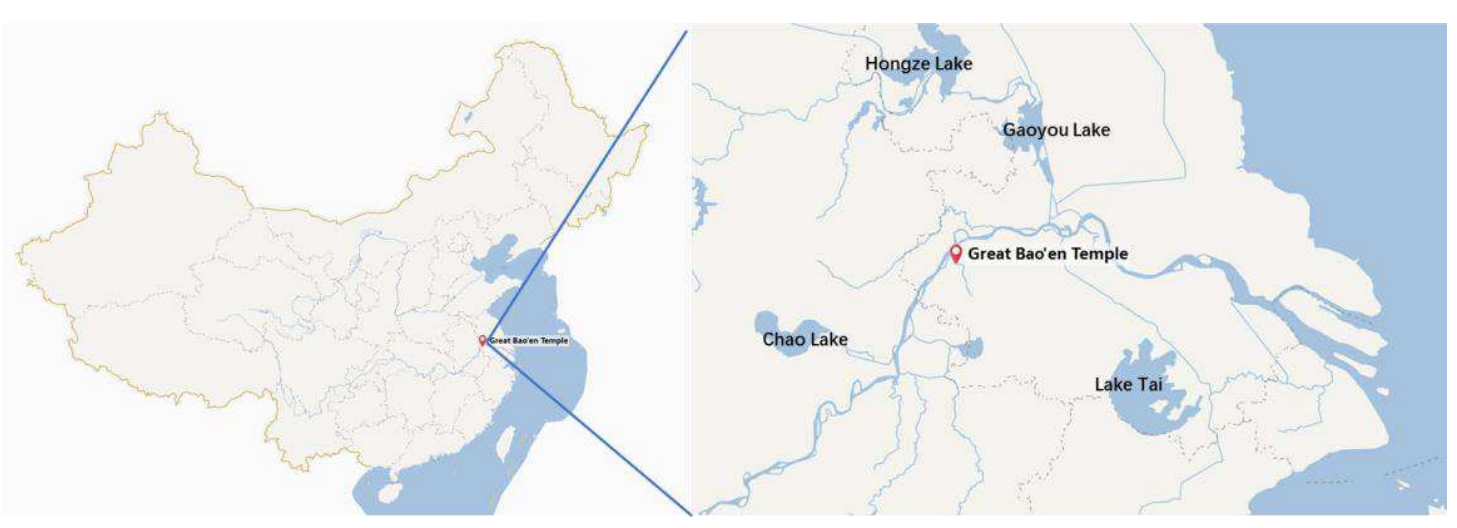

Figure 1 Location of Great Bao'en Temple

(a)

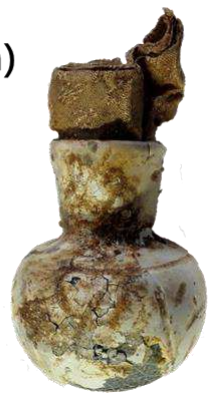

(b)

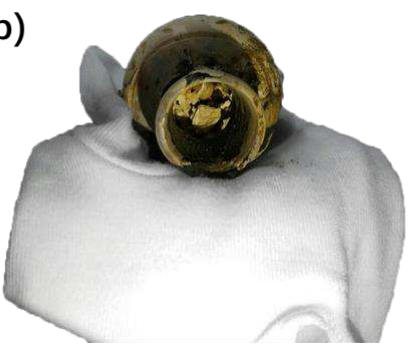

(c)

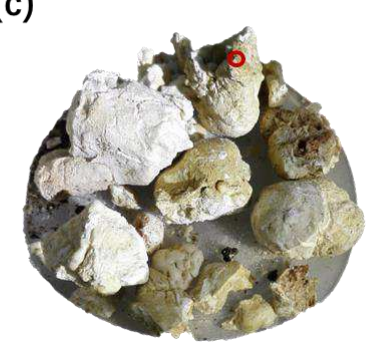

Figure 2 (a) The glass bottle numbered DG1:42, neck diameter: $2.6 \mathrm{~cm}$, abdominal diameter: $4.6 \mathrm{~cm}$, height: $6 \mathrm{~cm}$. (b) The glass bottle from the view of the bottle mouth (c) The incense taken from the glass bottle, sampling point was marked with a red circle.

\section{Results and Discussion}

General appearance of reference ambergris and archeology samples

Table 1 The photographs and property description of ambergris and archeological samples

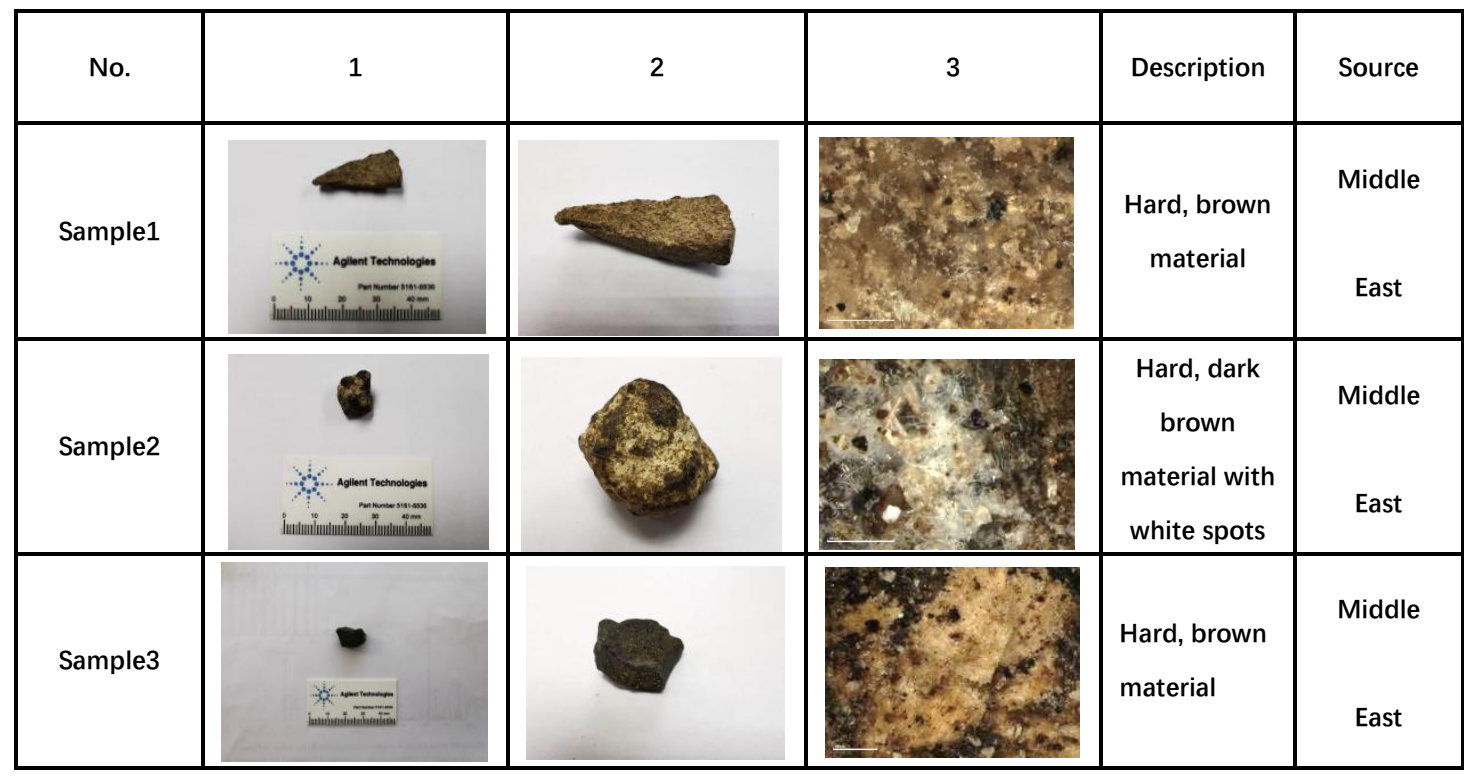




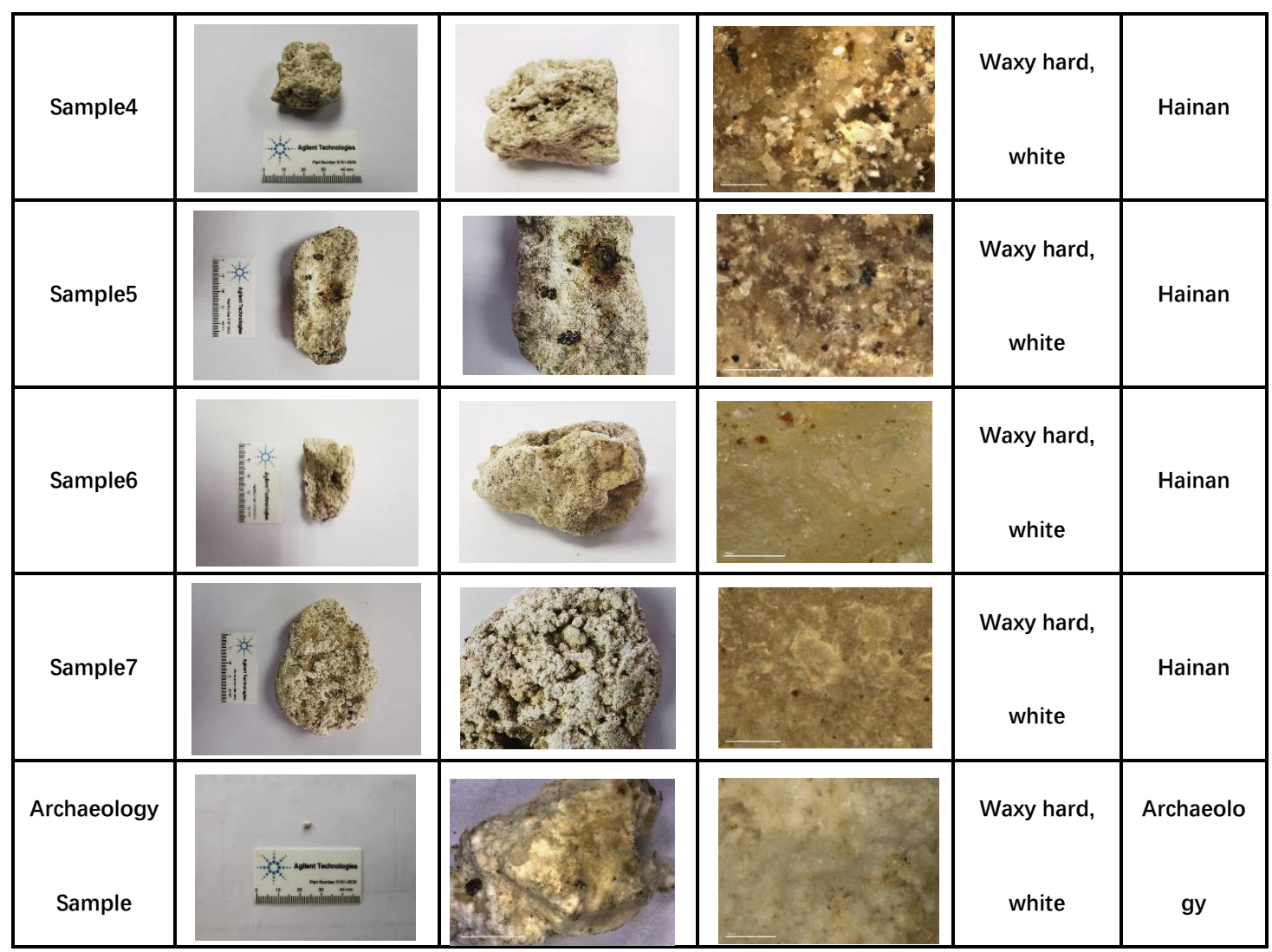

As shown in Table 1, the appearances of ambergris are various in the study. Sample 1,2,3 are brown materials with hard property. The sample 4,5,6,7 are white materials with waxy hard property. The appearance of an archaeological sample is more similar to sample 4,5,6,7. The two different morphologies were both reported previously. S. J. Rowland et al determined the radiocarbon $\left({ }^{14} \mathrm{C}\right)$ ages of the 40 samples, found that ambergris with lighter color has older age. ${ }^{[15]}$ Ambergris floating on the ocean might be naturally aged for hundred to thousand years. Previous ${ }^{14} \mathrm{C}$ radiocarbon dates revealed that a sample from Chile was about 1000 years old. ${ }^{[15]}$ Since the samples from Hainan are collected onshore or salvage on the sea surface, it might go through a natural aging process. However, the samples from the Middle East seem fresher.

\section{Results and Discussion}

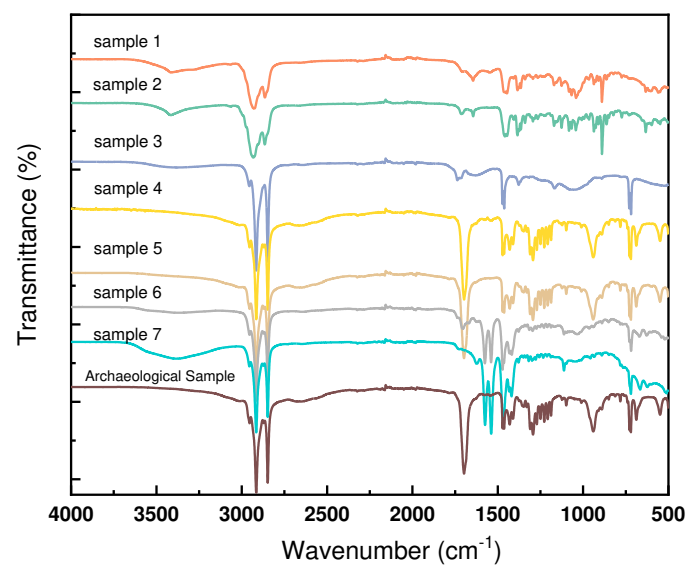


Figure 3 Infrared spectra of the reference samples and archeological sample

Table 2 Peak assignment for the IR spectra of reference samples and archeological sample with spectra matching result (The matching scores are accompanied in the bracket)

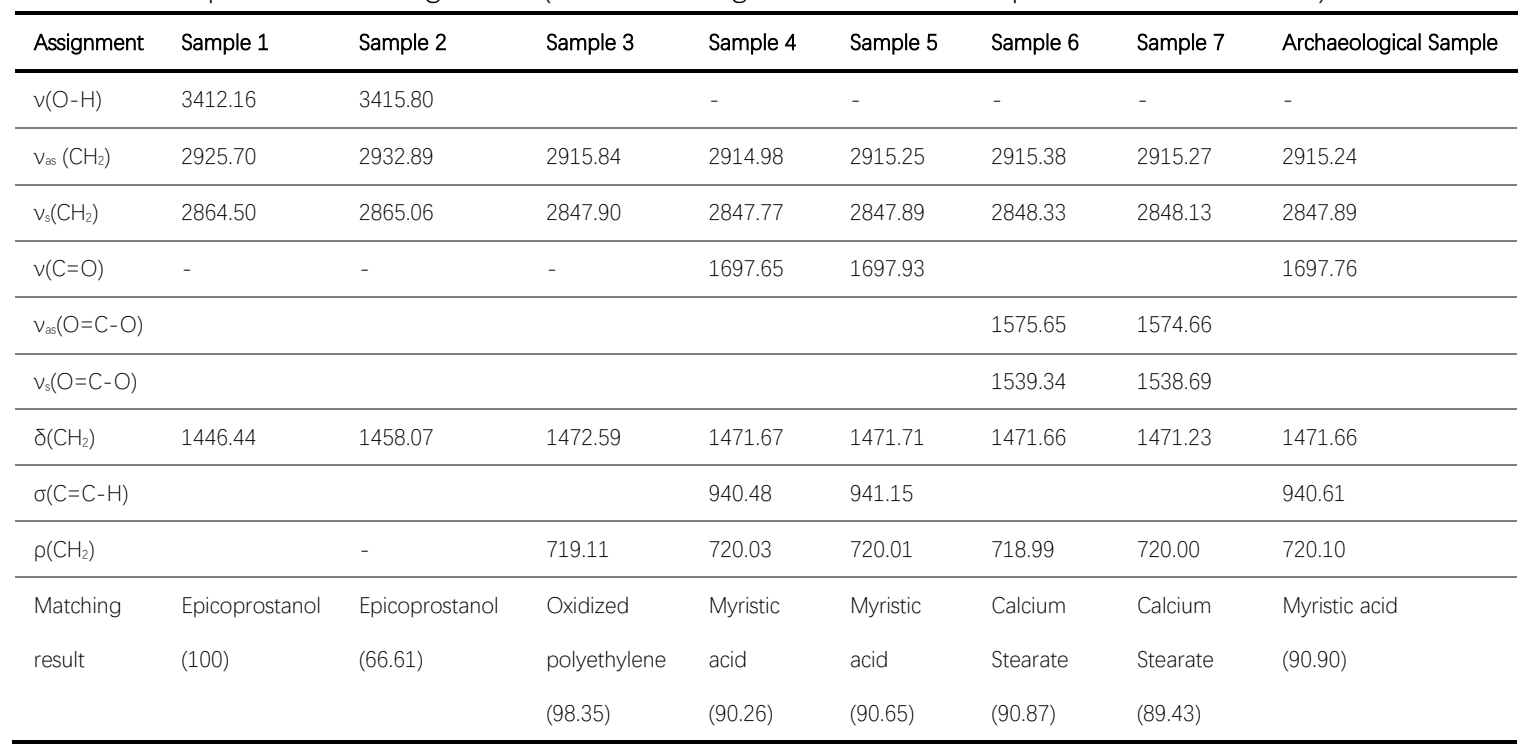

The results of FT-IR analysis are shown in Fig. 3, and all the samples, including both the archaeological samples and the reference samples, exhibited different spectra. For the reference sample 1 and 2 , the infrared transmittance peaks appear at $3412.16 \mathrm{~cm}^{-1}$ and $3415.80 \mathrm{~cm}^{-1}$, which are attributed to the stretching vibration band $v(\mathrm{O}-\mathrm{H})$. The peaks at $2925.70 \mathrm{~cm}^{-1}$ and $2932.89 \mathrm{~cm}^{-1}$ are associated with antisymmetric stretching vibration band $v_{\text {as }}\left(\mathrm{CH}_{2}\right)$. The peaks at $2865.50 \mathrm{~cm}^{-1}$ and $2865.06 \mathrm{~cm}^{-1}$ originated from stretching vibration band $v_{a s}\left(\mathrm{CH}_{2}\right)$, which indicate the presence of long-chain alkyl groups; the band at $1446.44 \mathrm{~cm}^{-1}$ and $1458.07 \mathrm{~cm}^{-1}$ represent bending vibrations of $\delta\left(\mathrm{CH}_{2}\right)$; the bands at $720.10 \mathrm{~cm}^{-1}$ are from planar rocking vibrations of $\rho\left(\mathrm{CH}_{2}\right)$. For the reference sample 3 , the IR spectrum profile is similar to sample 1 and 2, however there is no obvious peak for $v(\mathrm{O}-\mathrm{H})$. For the sample 4,5 and archaeological sample, the peaks of $\mathrm{v}(\mathrm{C}=0)$ appear at $1697.65 \mathrm{~cm}^{-1}, 1697.93 \mathrm{~cm}^{-1}$ and $1697.76 \mathrm{~cm}^{-1}$ respectively, which hints that the existence of fatty acids. The peaks at $940 \mathrm{~cm}^{-1}$, $941.15 \mathrm{~cm}^{-1}$ and $940.61 \mathrm{~cm}^{-1}$ for sample 4,5 and archaeological sample are attributed to the out-ofplane bending vibration of $\sigma(\mathrm{C}=\mathrm{C}-\mathrm{H})$, which confirming the presence of unsaturated hydrocarbon moiety. So far, the individual interpretation of the peaks does not easily provide specific material information. Although, by comparing the spectra to the IR spectra data base, the matching results provide the compounds with the highest possibility. As shown in Table 2, the spectra searching result reveals that the main component of sample 1,2 is epicoprostanol like steroid. The IR spectrum of sample 3 is most close to the oxidized polyethylene. The main compound of sample 4,5 and archaeological samples is myristic acid. The spectra of reference sample 6 and 7 are matched with calcium stearate. However, the IR spectra indicates no marker molecule of ambergris, therefore, further investigation using the other complementary analytical techniques was needed. 


\section{GC-QMS}

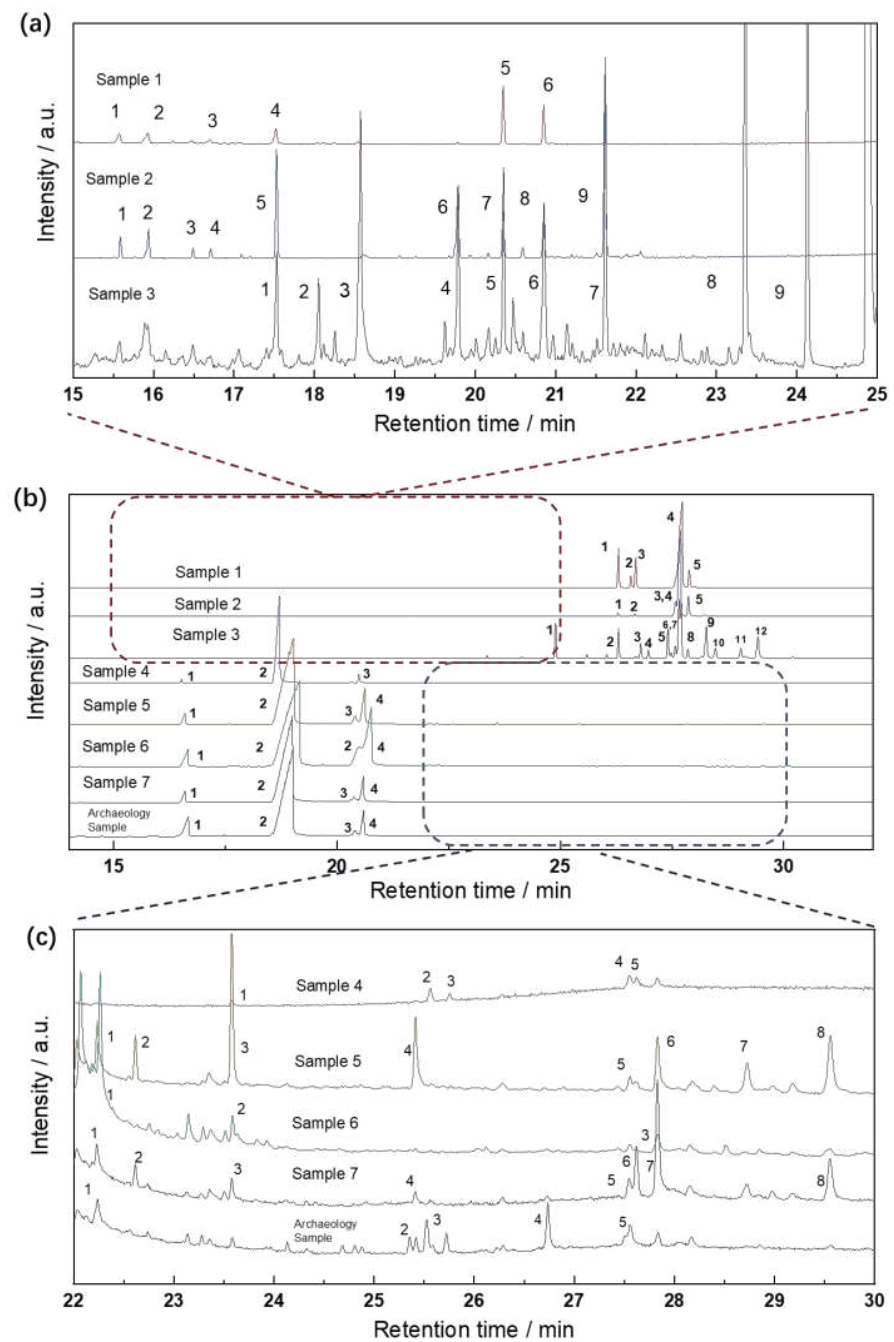

Figure 4 (a) The Total ion current of collected ambergris sample 1-3 in the retention time range of 15-25 min. (b) The Total ion current of collected ambergris samples and archeology sample. (c) The Total ion current of collected ambergris sample 4-7 and archeology sample in the retention time range of 22-30 min.

Table 3 The Molecular constituents detected and identified for the collected ambergris sample 1-3 in the retention time range of 15-25 min. The corresponding peak numbers are labeled in Fig. 1(a). The matching factors hitting in the NIST 14 data base are attached in the bracket.

\begin{tabular}{|c|c|c|c|c|}
\hline RT & Compound name & Sample 1 & Sample 2 & Sample 3 \\
\hline 15.569 & Bicyclo[2.2.2]octane, 1,2,3,6-tetramethyl- & $1(73.4)$ & $1(70.8)$ & \\
\hline 15.928 & Pristane & $2(86.9)$ & $2(93.2)$ & \\
\hline 16.490 & 1,5,9-Decatriene, 2,3,5,8-tetramethyl- & & $3(71.2)$ & \\
\hline 16.700 & Ambrox & $3(74.5)$ & $4(83.1)$ & \\
\hline 17.522 & Anthracene, 9-butyltetradecahydro- & $4(79.3)$ & $5(86.1)$ & $1(81.8)$ \\
\hline 18.056 & 7,9-Di-tert-butyl-1-oxaspiro(4,5)deca-6,9-diene-2,8-dione & & & $2(76.9)$ \\
\hline 18.572 & n-Hexadecanoic acid & & & $3(94.7)$ \\
\hline
\end{tabular}




\begin{tabular}{|c|c|c|c|c|}
\hline 19.782 & Sclareolide & & $6(94.6)$ & $4(94.4)$ \\
\hline 20.350 & 1-Carbomethoxy-1,2,5,5-tetramethyl-cis-decalin(1R,2S,4as,8as) & $5(76.1)$ & $7(78.5)$ & $5(75.6)$ \\
\hline 20.852 & 2-Buten-1-one, 1-(2,6,6-trimethyl-1-cyclohexen-1-yl)- & $6(77.1)$ & $8(64.3)$ & $6(79.4)$ \\
\hline 21.615 & Ambreinolide & & $9(92.7)$ & $7(92.2)$ \\
\hline 23.361 & Pentacosane & & & $8(96.1)$ \\
\hline 24.131 & Hexacosane & & & $9(95.6)$ \\
\hline
\end{tabular}

Table 4 The Total ion current of collected ambergris samples and archeology sample. The corresponding peak numbers are labeled in Fig. 1(b). The matching factors hitting in the NIST 14 data base are attached in the bracket.

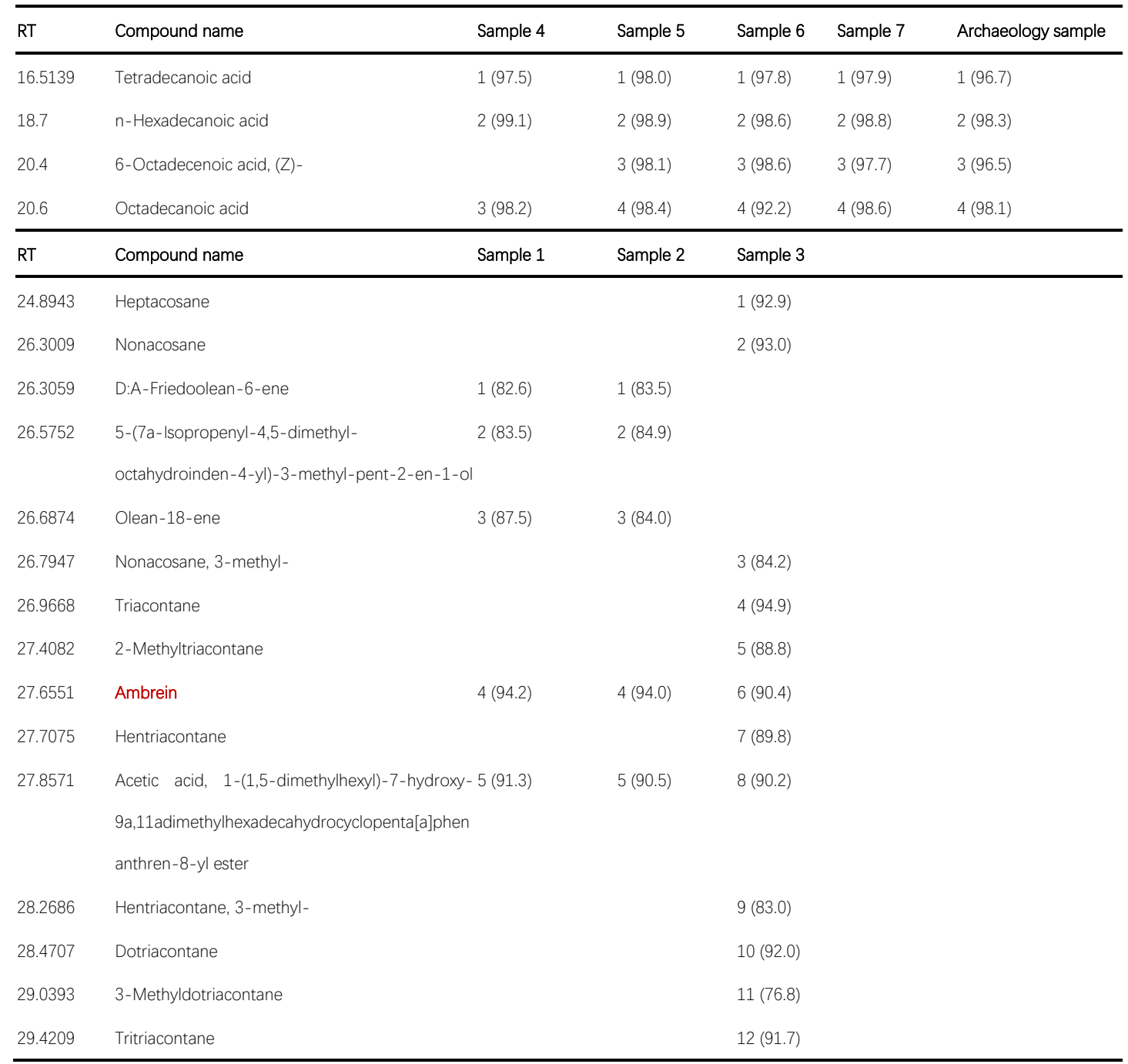

Table 5 The Molecular constituents detected and identified of the collected ambergris sample 4-7 and archeology sample in the retention time range of 22-30 min. The corresponding peak numbers are labeled in Fig. 1(c). The matching factors hitting in the NIST 14 data base are attached in the bracket.

\begin{tabular}{|c|c|c|c|c|c|c|}
\hline RT & Compound name & Sample 4 & Sample 5 & Sample 6 & Sample 7 & Archaeology sample \\
\hline 22.24 & Eicosanoic acid & & $1(90.7)$ & $1(94.1)$ & $1(81.6)$ & $1(60.8)$ \\
\hline 22.61 & $\begin{array}{l}\text { 2,2' - methylenebis[6-(1,1-dimethylethyl)-4- } \\
\text { methyl-Phenol }\end{array}$ & & $2(93.9)$ & & $2(86.0)$ & \\
\hline
\end{tabular}




\begin{tabular}{|c|c|c|c|c|c|c|}
\hline 23.575 & Phthalic acid, di(2-propylpentyl) ester & $1(94.1)$ & $3(95.6)$ & $2(89.8)$ & $3(78.1)$ & \\
\hline 25.358 & Tetradecanoic acid, dodecyl ester & & & & & $2(51.4)$ \\
\hline 25.4155 & (Z)-13-Docosenamide, & & $4(93.1)$ & & $4(65.0)$ & \\
\hline 25.53 & Cholest-4-ene & & & & & $3(87.2)$ \\
\hline 25.565 & Cholest-3-ene, (5.alpha.)- & $2(80.5)$ & & & & \\
\hline 25.76 & Cholest-2-ene, (5.alpha.)- & $3(84.6)$ & & & & \\
\hline 26.735 & Hexadecanoic acid, dodecyl ester & & & & & $4(82.9)$ \\
\hline 27.548 & $\begin{array}{l}\text { Cholestan-3-ol, (3.alpha.,5.beta.)-/ } \\
\text { epicoprostanol }\end{array}$ & $4(76.2)$ & $5(85.4)$ & & $5(78.8)$ & $5(61.0)$ \\
\hline 27.615 & Ambrein & $5(92.1)$ & & & $6(87.7)$ & \\
\hline 27.832 & $\begin{array}{l}\text { Cholestan-3-one, (5.beta.)/ } \\
\text { Coprostanone }\end{array}$ & & $6(88.5)$ & $3(83.0)$ & $7(87.0)$ & \\
\hline 28.7225 & $\begin{array}{l}\text { Cholestan-3-one, (5.alpha.)-/ } \\
\text { Cholestaneone }\end{array}$ & & $7(65.9)$ & & & \\
\hline 29.56 & $\gamma$-Sitosterol & & $8(77.7)$ & & $8(72.1)$ & \\
\hline
\end{tabular}

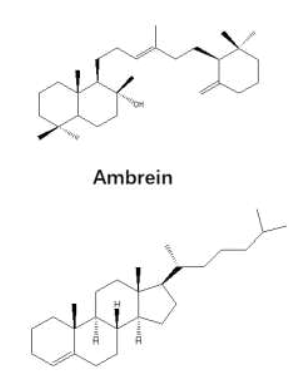

Cholest-4-ene

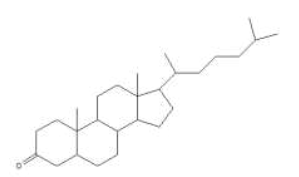

Cholestan-3-one, (5.beta.)
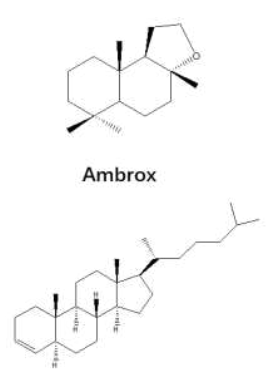

Cholest-3-ene, (5.alpha.)-

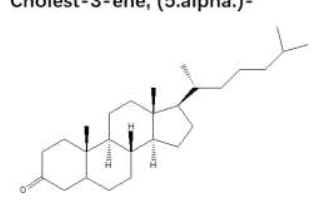

Cholestan-3-one, (5.alpha.)-
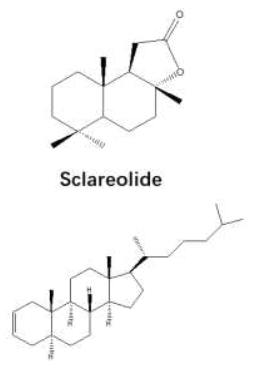

Cholest-2-ene, (5.alpha.)-
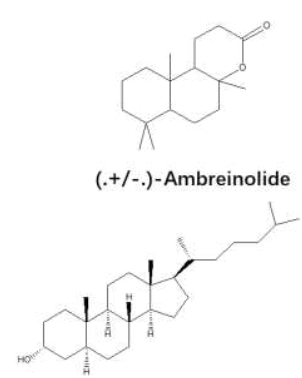

Cholestan-3-ol, (3.alpha.,5.beta.)-

Figure 5 The chemical structure of biomarker molecule in the ambergris.

The reference and archeological samples were preliminarily examined by GC-QMS. The total ion chromatograms (TICs) obtained from quadrupole mass spectrometer are shown in Figure 4. The identified compounds with their retention times, as well as the matching factor hitting in NIST 14 are reported in Table 3-5. As shown in Fig.4 (b), the profiles of TICs can be categorized into two groups. The eluents of sample 1,2 and 3 are mainly located at range from 22-30 min. The eluents of sample 4-7 and archaeological sample own earlier retention time, which is located at the range from 15 to $22 \mathrm{~min}$. Thus, the main components are different between the two categories. As shown in Table 3, sample 1-3 contain ambrein, which is the main biomarker molecule for ambergris. Since literature does not indicate any other natural source of ambrein. Exclude artificial addition, it is assumed, therefore, that ambrein is unique to ambergris and detection of ambrein is tantamount to detecting ambergris. In the sample 1 to 3 , the acetylated steroid can be explained by the prevalent existence of steroid in the ambergris. Besides, there are several triterpenoid compounds such as olean-18-ene in sample 1, 2, and linear chain 
saturated alkanes range from C27 to C33 in sample 3. Since there is no similar case in literature, it might come from unknown biological process or environmentally influenced adsorption process. The trace constituents of sample 1 to 3 are displayed in Fig. 4 (a). The compounds associated artefactual ambratrienes, such as Ambrox ${ }^{\oplus}$, ambreinolide and sclareolide were detected, along with the pristane and other long chain alkanes and alkenes. Among them, Ambrox ${ }^{\oplus}$ and ambreinolide are previously thought to be produced from the dehydration in the GC injector and the pristane originates from sorption of marine planktonic oils. ${ }^{[16]}$ Even though, the present of sclareolide hints that the reference sample 2 and 3 might be contaminated by artificial chemical products. Since, the sclareolide is an intermediate product originated from the artificial synthesis of Ambrox ${ }^{\circledR}{ }^{[17]}$ So, we can't tell if sample 2 and 3 are pure natural ambergris or not, however they are good enough as reference material. In the case of sample 4-7 and archaeological sample, a large amount of the linear monocarboxylic acid present including saturated fatty acid range from C14 to C18 with C16 being the most abundant, and unsaturated fatty acid C18:1. Previous study of the saponified portion of ambergris also found various fatty acids, such as stearic, oleic, linoleic acid. ${ }^{[18]}$ The minor components in the range of 22 to $30 \mathrm{~min}$ for sample 4 to 7 and archeology are shown in Fig 4 (c). Ambrein was detected in the sample 4 and 7 as well. A number of faecal steroids such as epicoprostanol, coprostanone and so on, though variable, were detected in the sample 4 to 7 and archeological sample. It is consistent with the early investigations of the chemistry of ambergris, in which the major components to be the triterpene alcohol, ambrein, epicoprostanol, and coprostanone. ${ }^{[19,20]}$ Even though the ambrein was negative detected in the archaeological sample, it's TIC profile is highly consistent with the ambergris references (Sample 4-7). Ambergris, a metabolite of the sperm whale, is probably produced by intestinal microorganisms in the whales, ${ }^{[4]}$ likely from the partial cyclisation of squalene. ${ }^{[21,22]}$ Accounts of the proportions of ambrein (I) in individual ambergris samples vary, from a few per cent to most of the whole mass. ${ }^{[23]}$ Therefore, we preliminary infer that the archaeological sample is a piece of ambergris with extremely low content of ambrein.

\section{GC-QTOF-MS}

(a) $\times 10$

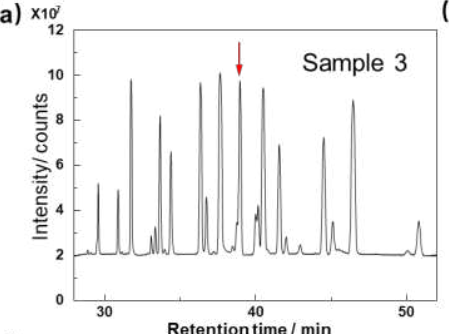

(d)

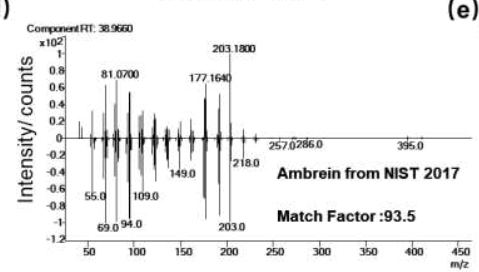

(b) $\times 10$

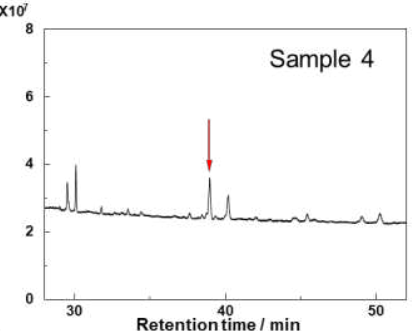

(e)

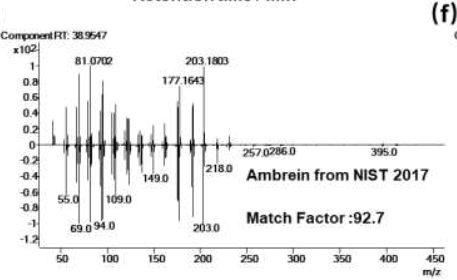

(c) $\times 10$

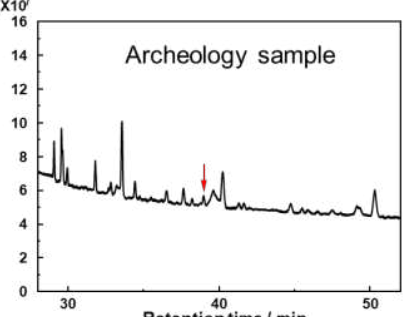

(f)

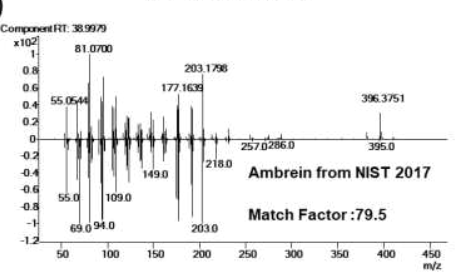

Figure 6 (a)The Total ion current of collected ambergris sample 3 in the retention time range of 28-52 min; (b) The Total ion current of collected ambergris sample 4 in the retention time range of 28-52 min; (c) The Total ion current of archaeology sample in the retention time range of 2852 min; (d) The mass spectrum of the peak marked by red arrow in Fig.3 (a); (e) The mass spectrum of the peak marked by red arrow in Fig. 3 (b); ( $f$ ) The mass spectrum of the peak 
marked by red arrow in Fig. 3 (c).

Table 6 The formula and mass number of characteristic ions of ambrein and suspected interfering ions.

\begin{tabular}{llll}
\hline & Formula & Mass number & ion source \\
\hline Molecular ion & {$\left[\mathrm{C}_{30} \mathrm{H}_{52} \mathrm{O}\right]^{+}$} & 428.4013 & \\
Fragment ion & {$\left[\mathrm{C}_{30} \mathrm{H}_{50}\right]^{+}$} & 410.3907 & {$\left[\mathrm{C}_{30} \mathrm{H}_{52} \mathrm{O}\right]-\mathrm{H}_{2} \mathrm{O}$} \\
Fragment ion & {$\left[\mathrm{C}_{29} \mathrm{H}_{47}\right]^{+}$} & 395.3672 & {$\left[\mathrm{C}_{30} \mathrm{H}_{52} \mathrm{O}\right]-\mathrm{H}_{2} \mathrm{O}-\mathrm{CH}_{3}$} \\
Suspected interfering ions & {$\left[\mathrm{C}_{29} \mathrm{H}_{48}\right]^{+}$} & 396.3751 & \\
\hline
\end{tabular}

(a)

(b) $\times$,

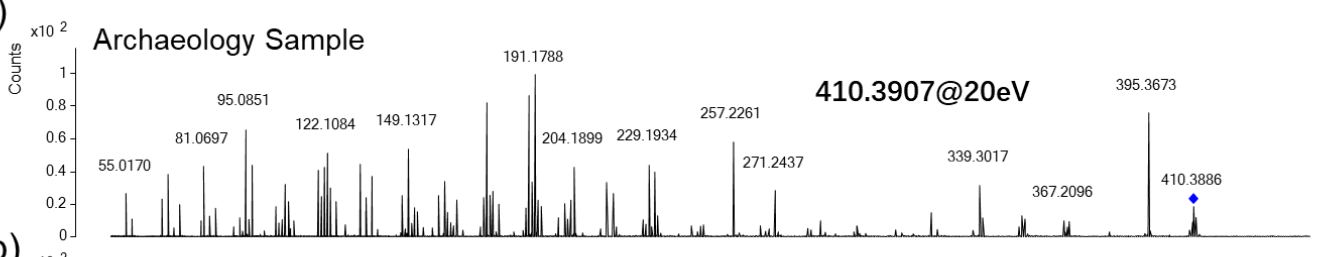

(c)
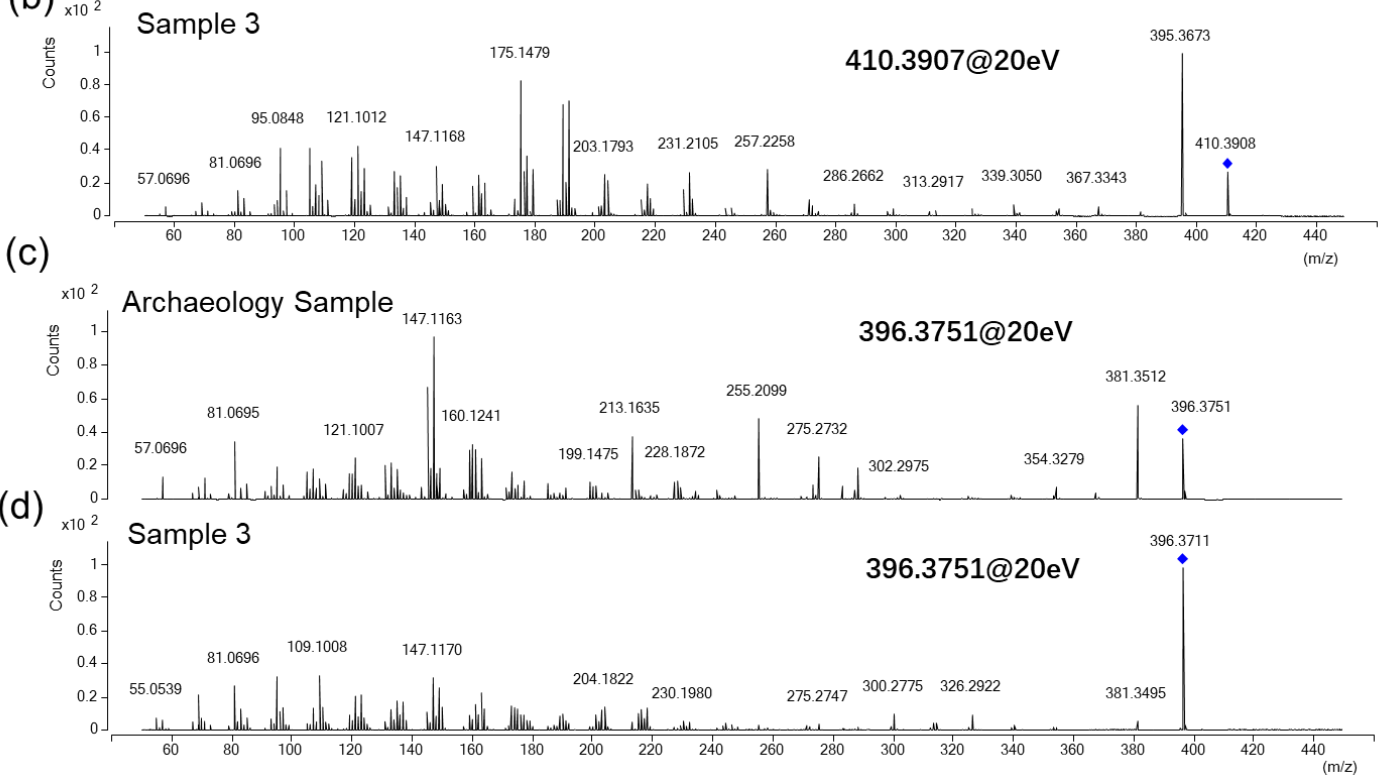

Figure 7 (a), (b) The secondary mass spectrum of ion $\mathrm{m} / \mathrm{z}=410.3907$ extracted in archaeology and sample 3 with the collision energy at $20 \mathrm{eV}$. (c), (d) The secondary mass spectrum of ion $\mathrm{m} / \mathrm{z}=396.3751$ extracted in archaeology and sample 3 with the collision energy at $20 \mathrm{eV}$.

In order to find convincing evidence. The ultra-high-resolution QTOF-MS was applied. The GC condition was adjusted to get good separation, and applied with large volume injection mode to reduce the solvent noise. As shown in Fig.6, the retention time of ambrein was 38.9 min. The peak with RT at 38.9 was detected in the reference sample 3,4 and archeological sample. The comparison of mass spectra is displayed in Fig.6 (d)-(f). The characteristic ion fragments of ambrein are $\mathrm{m} / \mathrm{z}$ at 203, 177, 81. For sample 3, the detected ion fragments are at 203.1800,177.1640,81.0700, respectively; for sample 4, the detected ion fragments are at 203.1803,177.1643,81.0702. respectively; for archaeological sample, the detected ion fragments are at 203.1798,177.1639,81.0700, respectively. In addition, the matching factor of the eluent at 38.9 min for sample 3, sample 4 and archeological sample are 93.5, 92.7 and 79.5 respectively. 
The lower matching factor for archeological sample might be due to the ion fragment $\mathrm{m} / \mathrm{z}=396.3751$, which is suspected not to originate from the ambrein molecule. Table 6 gives the ion fragment identification of ambrein and suspected interfering ions. The molecular ion for ambrein is 428.4013, the fragment ion with a $\mathrm{H}_{2} \mathrm{O}$ loss is at $\mathrm{m} / \mathrm{z}=410.3907$. The fragment ion with a $\mathrm{H}_{2} \mathrm{O}$ and $-\mathrm{CH}_{3}$ loss is at $\mathrm{m} / \mathrm{z}=395.3672$. In addition, the suspected interfering ion at $\mathrm{m} / \mathrm{z}=396.3751$ was further excluded via the secondary mass spectra. According to Fig.7, the secondary mass spectra of 410.3907 fragment has the similar profile for the archeological sample and sample 3. However, the secondary mass spectra of 396.3751 fragment extracted from archeological sample and sample 3 are different. In conclusion, the fragment 396.3751 is a coelution with ambrein for archeological sample.

\section{Incense in the Song Dynasty}

The earliest literature record about Ambergris in China is "Youyang Zazu" <酉阳杂沮> from the Tang Dynasty: "The City Berbera is located in the southwest sea, there are ivories and ambergris" <拔拔力国, 在西南海中, 土地唯有象牙及阿末香> ${ }^{[24]}$ Even so, it is an anecdote from abroad. In the Song Dynasty, the use of incense was prosperous and the trade of incense flourished. Typically, the exotic incense sources of incense were plentiful at that time, such as the incense imported from Arab region are olibanum, ambergris and rose water. It was supported by the fact that a ship excavated from Quanzhou Bay used to be an incense trade ship and carried a large amount of dalbergia wood, olibanum. ${ }^{[25,26]}$ Among these incenses, ambergris is a very rare exotic incense and only employed by people with wealth and power. "Tieweishan Congtan" described the emperors of the Song Dynasty giving gifts of incense to ministers and guards: The royal Treasury of Feng Chen got two pieces of ambergris, the ambergris was given to the ministers and guards. The ambergris has a large block and an ordinary appearance. Take a little bit to burn with fire, then the aroma of ambergris will fill the room, and last for days. The emperor was greatly surprised and ordered to count the remaining ambergris, no matter how much, to reclaim it, put it in the palace, and called it ancient ambergris. <时于奉宸中的龙诞二，……香则 多分赐大臣近侍。其模制甚大而质古, 外视不大佳。每以一豆火蓺之, 辄做异花气, 芬郁满 座。终日略不歇。于是太上大奇之, 命籍被此者, 随数多寡, 复收取以归中禁。因号曰“古龙 涎” >. In the Song Dynasty, incense had a variety of usages in people's lives, such as sacrificial functions and practical functions of removing impurities and cleanness. In the upper society, it was a symbol of power, and in the life of common people, it was also a fashion to appreciate the fragrance of incense and watch the shape of smoke. Herein, the incense was excavated from iron casket outside the Ashoka tower and archaeologists think it is related to religious offerings. The incense book (Xiang sheng) from the Ming dynasty recorded the relationship between incense and Buddhism. The "Xiangyin Dinggu (香印顶骨)" is a very classic offering situation described as following: the bones of the Buddha are placed in the casket or pagoda. Believers who want to learn about good and evil, etc., use the broken pieces of incense clay to imprint on the parietal bone. With the guidance of the Buddha's blessing, the incense clay gives rise to a brand-new texture. In addition, according to the previous study, there are olibanum and aquilaria sinensis excavated from the Changgan underground stupa palace. They are stored in different containers, such as jade bowl, silver vase, silver box and so on. Hence the ambergris reported here was applied with religious function as an important offering. 


\section{Conclusion}

The suspected ambergris residues in glass bottle of Song Dynasty excavated from Great Bao'en Temple historical site were characterized using FT-IR, GC-QMS and GC-QTOF-MS. The characterization components of 7 modern ambergris were screened and used as reference. By preliminary screening, the composition features of ambergris extract were identified. Besides the main biomarker ambrein, other steroids such as epicoprostanol and coprostanone were identified. Further high-resolution gas chromatography mass spectrometry with solvent vent mode detected the ambrein in the archaeological sample and provided the direct evidence that organic residue unearthed in the glass bottles was ambergris. This is the earliest ambergris sample which was manipulated by ancient people. It enriched scholarly knowledge about the incense materials used in ancient China, demonstrated the well-developed overseas incense trade and the solemn Buddhist culture of using incense in the Song Dynasty. We will also continue to pay close attention to the analysis and research of ancient incense unearthed or to be unearthed.

\section{Declaration of interest}

No potential conflict of interest was reported by the author(s)

\section{Funding}

This research is financially supported by the Scientific Foundation of National Museum of China.

\section{Reference}

[1] Q.W. Liren Huang, Yu Lei, Bushun Dong, Jianguo Zhang, Hai Wang, Qiliang Xiong, Lihua Sheng, Haining Qi, Juping Gong, The Excavation of the Pagoda Foundation and Undergraound Palace of the Grand Bao'en Temple in Nanjing, Cultural Relics, (2015) 4-52, htttp://doi.org/, Chinese.

[2] Y.S. Zhiguo Zhang, Dawa Sheng, Qinglin Ma, Ancient gold and silver ware, glassware, incense Protection technology -- Nanjing Ashoka Tower and unearthed cultural Relics protection, Science Press, Beijing, 2014.

[3] K.H. Dannenfeldt, Ambergris: The Search for Its Origin, History of Science society, 73 (1982) 382-397, htttp://doi.org/ 10.1086/353040 English.

[4] R. Clarke, The origin of ambergris, Latin American Journal of Aquatic Mammals, 5 (2006), htttp://doi.org/ 10.5597/lajam00087, English.

[5] M.A. López-Bascón, F. Priego-Capote, A. Peralbo-Molina, M. Calderón-Santiago, L.D. Castro, Influence of the collection tube on metabolomic changes in serum and plasma, Talanta, 150 (2016) 681-689, htttp://doi.org/ 10.1016/j.talanta.2015.12.079, English.

[6] A. Schottenhammer, The emporium of the world: maritime Quanzhou, 1000-1400, Brill, 2001.

[7] L. Blanco-Zubiaguirre, M. Olivares, K. Castro, J.A. Carrero, C. Garcia-Benito, J.A. Garcia-Serrano, J. Perez-Perez, J. Perez-Arantegui, Wine markers in archeological potteries: detection by GC-MS at ultratrace levels, Anal Bioanal Chem, 411 (2019) 6711-6722, htttp://doi.org/ 10.1007/s00216- 
019-02044-1.

[8] H. Han, S. Wei, J. Yang, L. Guan, W. Li, Characterization of the residues in Han Dynasty bronze lamps by pyrolysis-gas chromatography-mass spectrometry, Herit Sci, 7 (2019), htttp://doi.org/ 10.1186/s40494-019-0279-5, English.

[9] M. Moniruzzaman, I. Rodriguez, M. Ramil, R. Cela, S.A. Sulaiman, S.H. Gan, Assessment of gas chromatography time-of-flight accurate mass spectrometry for identification of volatile and semivolatile compounds in honey, Talanta, 129 (2014) 505-515, htttp://doi.org/ 10.1016/j.talanta.2014.06.019, English.

[10] Y. Xia, F. Zhang, W. Wang, Y. Guo, Analysis of volatile compounds from Siraitia grosvenorii by headspace solid-phase microextraction and gas chromatography-quadrupole time-of-flight mass spectrometry, J Chromatogr Sci, 53 (2015) 1-7, htttp://doi.org/ 10.1093/chromsci/bmu012, English.

[11] L. Aifei, W. Yawei, X. Mo, Z. Zongshan, Z. Bin, W. Jinpeng, Y. Peng, Characterization of polychlorinated biphenyl congeners in surface sediments of the Changjiang Estuary and adjacent shelf by high-resolution sampling and high-resolution mass spectrometry, Marine Pollution Bulletin, (2017), htttp://doi.org/ 10.1016/j.marpolbul.2017.07.036, English.

[12] X. Zhu, M. Liu, Z. Liu, Y. Li, S. Tian, Direct and Rapid Quantitative Analysis of Alkyldibenzothiophenes in Deeply Hydrodesulfurized Diesel Fuel by Gas Chromatography Quadrupole Time-of-Flight Mass Spectrometry, Energy \& Fuels, 31 (2017) 9125-9131, htttp://doi.org/ 10.1021/acs.energyfuels.7b01289, English.

[13] X. Chen, F. Zhang, H. Yao, J. Wang, D. Qi, Y. Guo, Analyzing multiple pesticides in tobacco leaf using gas chromatography with quadrupole time-of-flight mass spectrometry, J Sep Sci, 41 (2018) 1983-1989, htttp://doi.org/ 10.1002/jssc.201701029, English.

[14] V. Shevyrin, Y. Shafran, Distinguishing of 2-MAPB and 6-MAPB: Solution of the problem, Journal of Mass Spectrometry, 52 (2017) 633-637, htttp://doi.org/ 10.1002/jms.3970, English.

[15] S.J. Rowland, P.A. Sutton, T.D.J. Knowles, The age of ambergris, Nat Prod Res, 33 (2019) 3134 3142, htttp://doi.org/ 10.1080/14786419.2018.1523163, English.

[16] M.J. Wilde, W.J. Robson, P.A. Sutton, S.J. Rowland, Volatile and semi-volatile components of jetsam ambergris, Nat Prod Res, (2019) 1-6, htttp://doi.org/ 10.1080/14786419.2019.1607855, English.

[17] C.S. Wang Wenjun, Dai Qianhuan, The Composition of Ambergris and the Development of the Synthesis of ( -)-Ambrox, Chinese Journal of Organic Chemistry, 21 (2001), htttp://doi.org/ 10.3321/j.issn:0253-2786.2001.03.001, Chinese.

[18] S.A. Taha, Chemical investigation of the internal secretion of the sperm blue whale, Pakistan Journal of Pharmaceutical ences, 2 (1989) 105-110, htttp://doi.org/, English.

[19] R.T.A. Thomas F. Governo, Manfred J.Prager, Gas-Liquid Chromatographic-Mass Spectrometric Detection and Identification of Ambergris, Journal of the AOAC, 1 (1977), htttp://doi.org/ 10.1093/jaoac/60.1.160, English.

[20] S.J. Rowland, P.A. Sutton, Chromatographic and spectral studies of jetsam and archived ambergris, Nat Prod Res, 31 (2017) 1752-1757, htttp://doi.org/ 10.1080/14786419.2017.1290618, English.

[21] T. Oritani, K. Yamashita, M. Matsui, Chemical studies on ambergris, Agricultural and Biological Chemistry, 34 (1970) 1244-1248, htttp://doi.org/ 10.1271/bbb1961.34.1244, English.

[22] D. Ueda, T. Hoshino, T. Sato, Cyclization of squalene from both termini: identification of an 
onoceroid synthase and enzymatic synthesis of ambrein, Journal of the American Chemical Society, 135 (2013) 18335-18338, htttp://doi.org/ 10.1021/ja4107226, English.

[23] A. Baynes-Cope, Analyses of samples of ambergris, Nature, 193 (1962) 978-979, htttp://doi.org/ 10.1038/193978a0, English.

[24] Z. Yang, Xiangshi, Shenghuo Dushu Xinzhi Sanlian Book Store, Beijing, 2020.

[25] R. Chen, X. Mou, J. Dai, The identification and textual research of incense in the Shipwreck of Quanzhou Bay in Song Dynasty, Shanghai Journal of Traditional Chinese Medicine, (1979), htttp://doi.org/ 10. 16305 /j . 1007 -1334. 1979. 05. 022.

[26] W. Zhang, TLC identification of Frankincense from shipwreck in Quanzhou Bay song Dynasty, Journal of Maritime History Studies, (1982), htttp://doi.org/. 


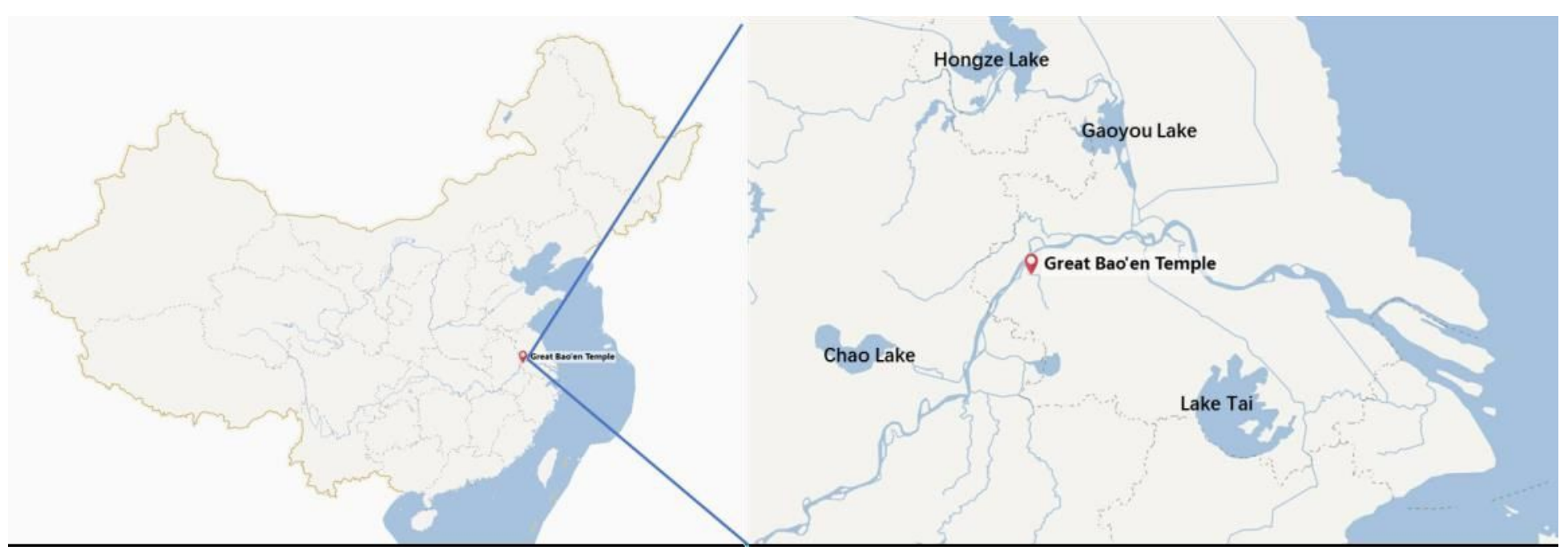

Figure 1

Location of Great Bao'en Temple. Note: The designations employed and the presentation of the material on this map do not imply the expression of any opinion whatsoever on the part of Research Square concerning the legal status of any country, territory, city or area or of its authorities, or concerning the delimitation of its frontiers or boundaries. This map has been provided by the authors.
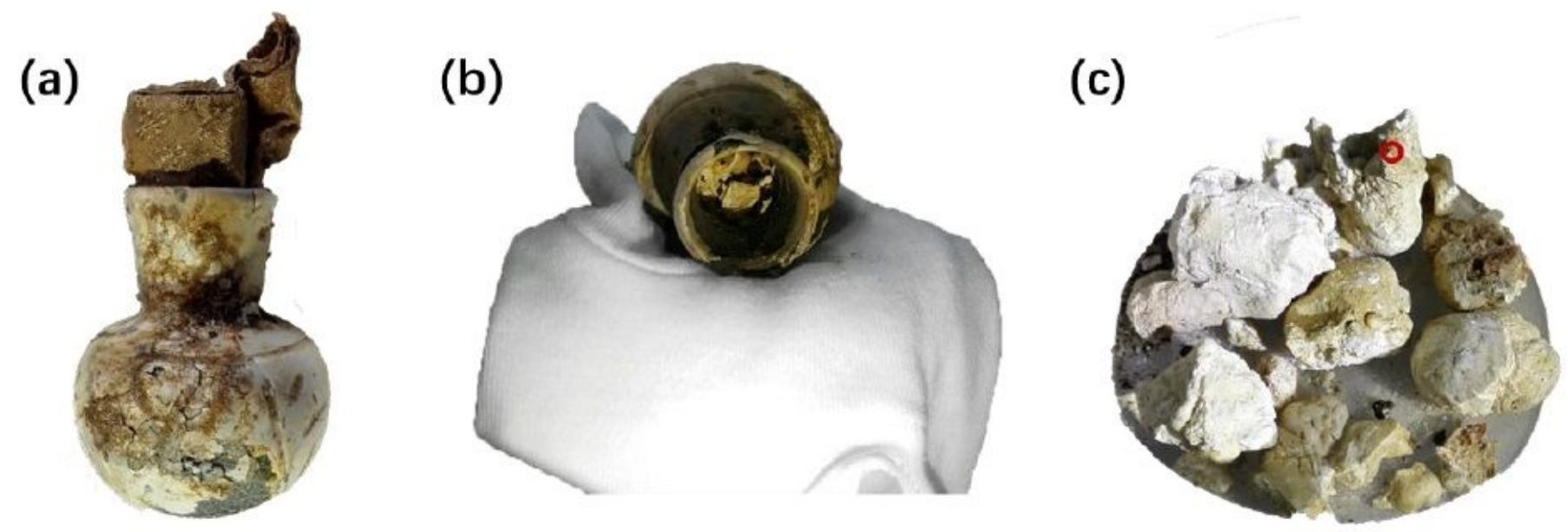

\section{Figure 2}

( The glass bottle numbered DG1:42, $\mathrm{n}$ eck diameter : $2.6 \mathrm{~cm}$, a bdominal diameter : $4.6 \mathrm{~cm}$, h eight: 6 $\mathrm{cm}$. (b) The glass bottle from the view of the bottle mouth (c) The incense taken from the glass bottle sampling point was marked with a red circle. 


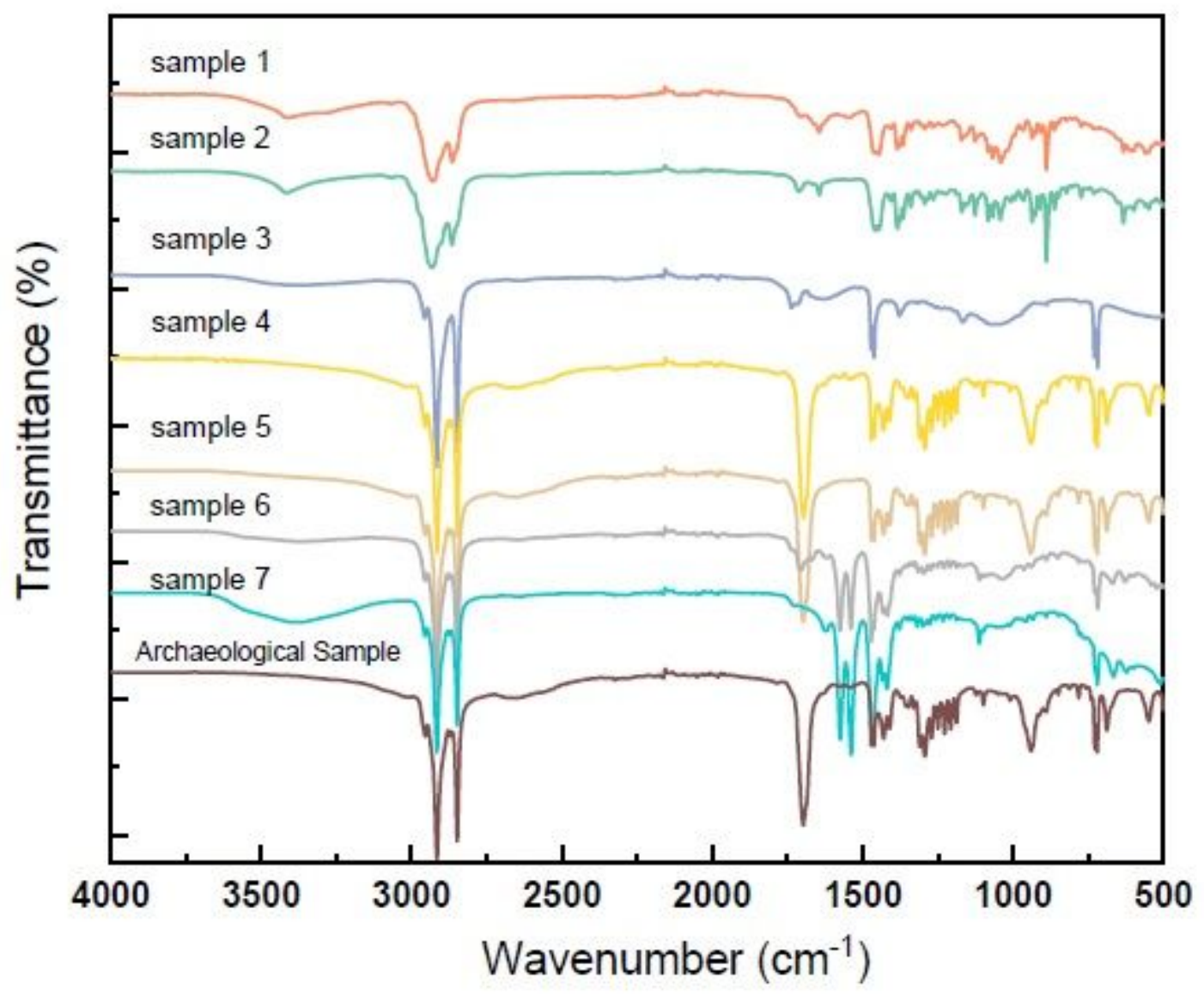

Figure 3

Infrared spectra of the reference samples and archeological sample 

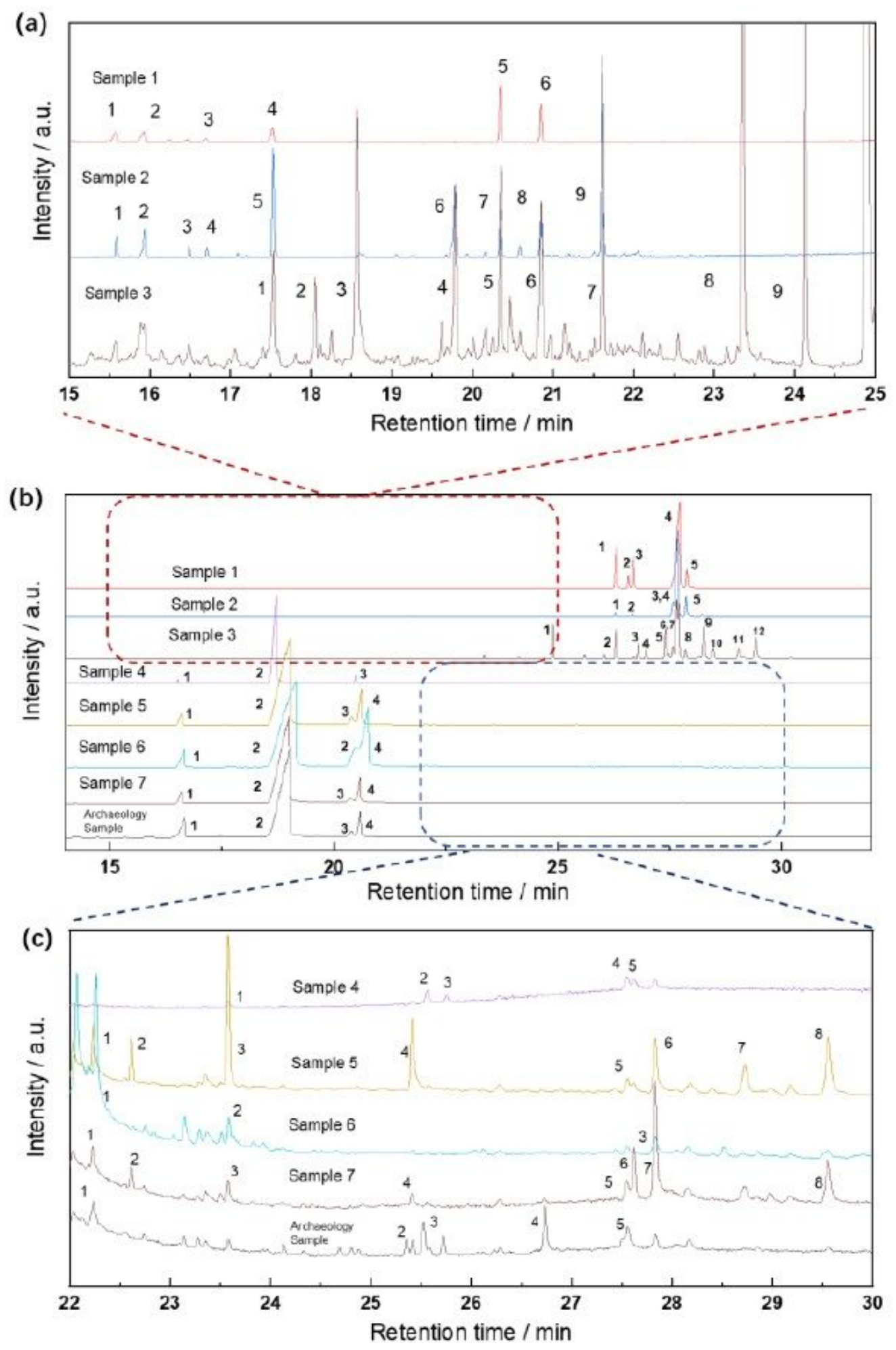

\section{Figure 4}

(a) The Total ion current of collected ambergris sample 13 in the retention time range of 1525 min. (b) The Total ion current of collected ambergris samples and archeology sample. (c) The Total ion current of collected ambergris sample 47 and archeology sample in the retention time range of $2230 \mathrm{~min}$ 


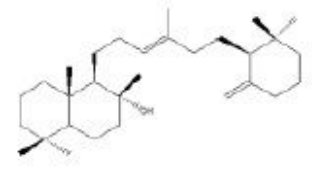

Ambrein

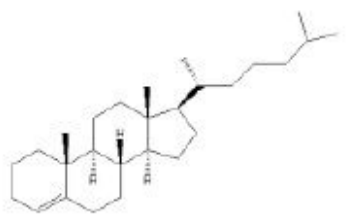

Cholest-4-ene

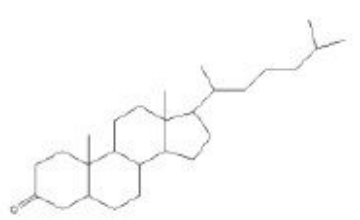

Cholestan-3-one, (5.beta.)

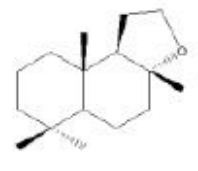

Ambrox

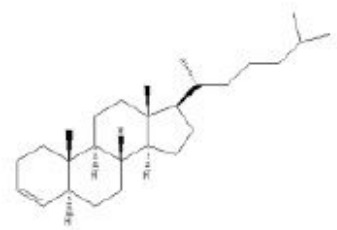

Cholest-3-ene, (5.alpha.)-

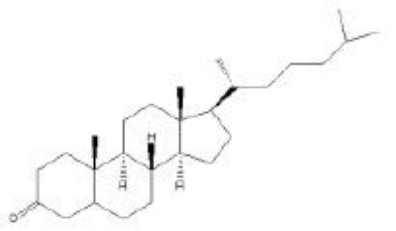

Cholestan-3-one, (5.alpha.)-

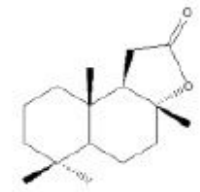

Sclareolide

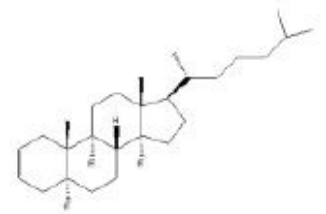

Cholest-2-ene, (5.alpha.)-

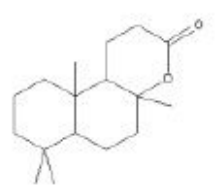

(.+/-.)-Ambreinolide

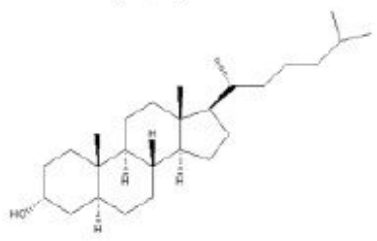

Cholestan-3-ol, (3.alpha.,5.beta.)-

\section{Figure 5}

The chemical structure of biomarker molecule in the ambergris.

(a) $x+1$

(d)
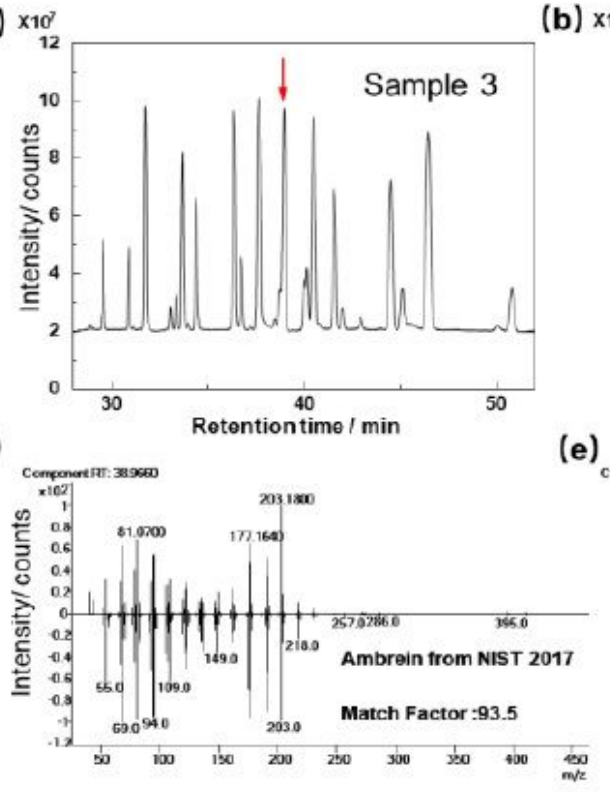

(b) $\times 10^{7}$

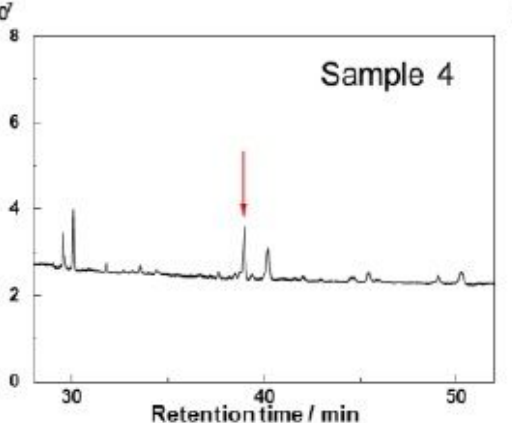

(e)

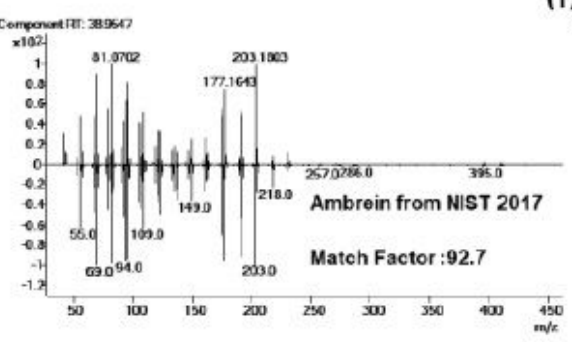

(c) $\times 10^{\circ}$

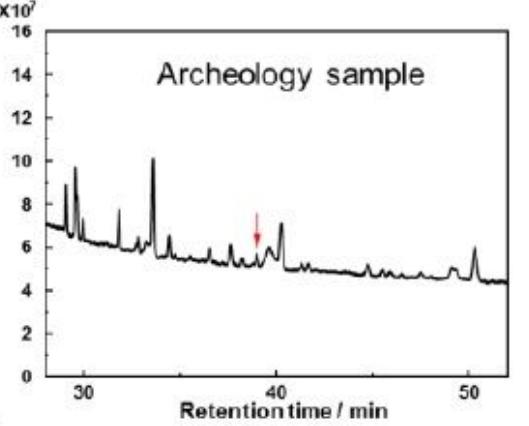

(f)

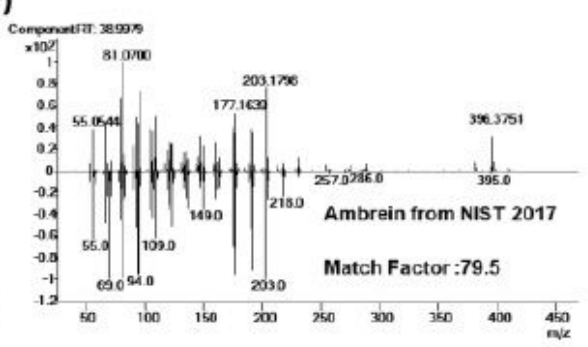

Figure 6

(a)The Total ion current of collected ambergris sample 3 in the retention time range of $2852 \mathrm{~min}$; (b) The Total ion current of collected ambergris sample 4 in the retention time range of 2852 min ; (c) The Total ion current of archaeology sample in the retention time range of $2852 \mathrm{~min}$ d) The mass spectrum of the peak marked by red arrow in Fig 3 (a) (e) The mass spectrum of the peak marked by red arrow in Fig 3 (b) b); (f) The mass spectrum of the peak marked by red marked by red arrow in Figarrow in Fig. 3 (c). 
(a)

(b) $\times 102$

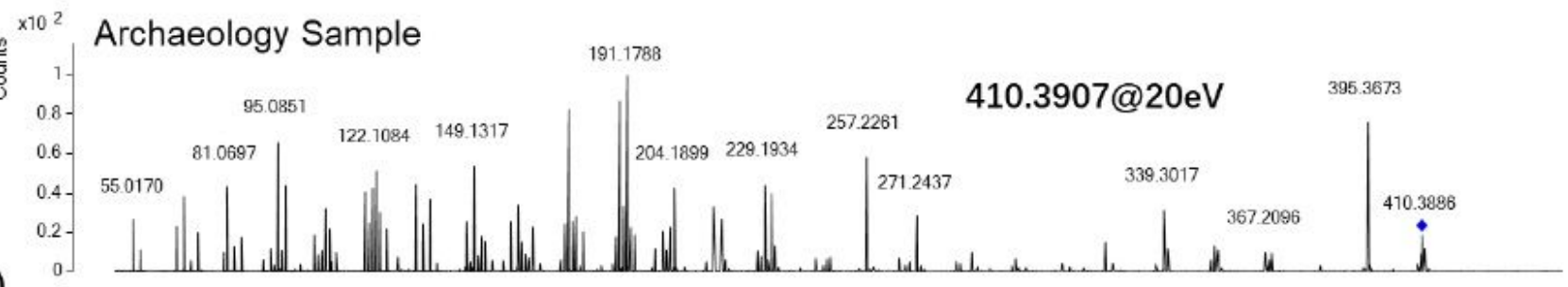

(c)
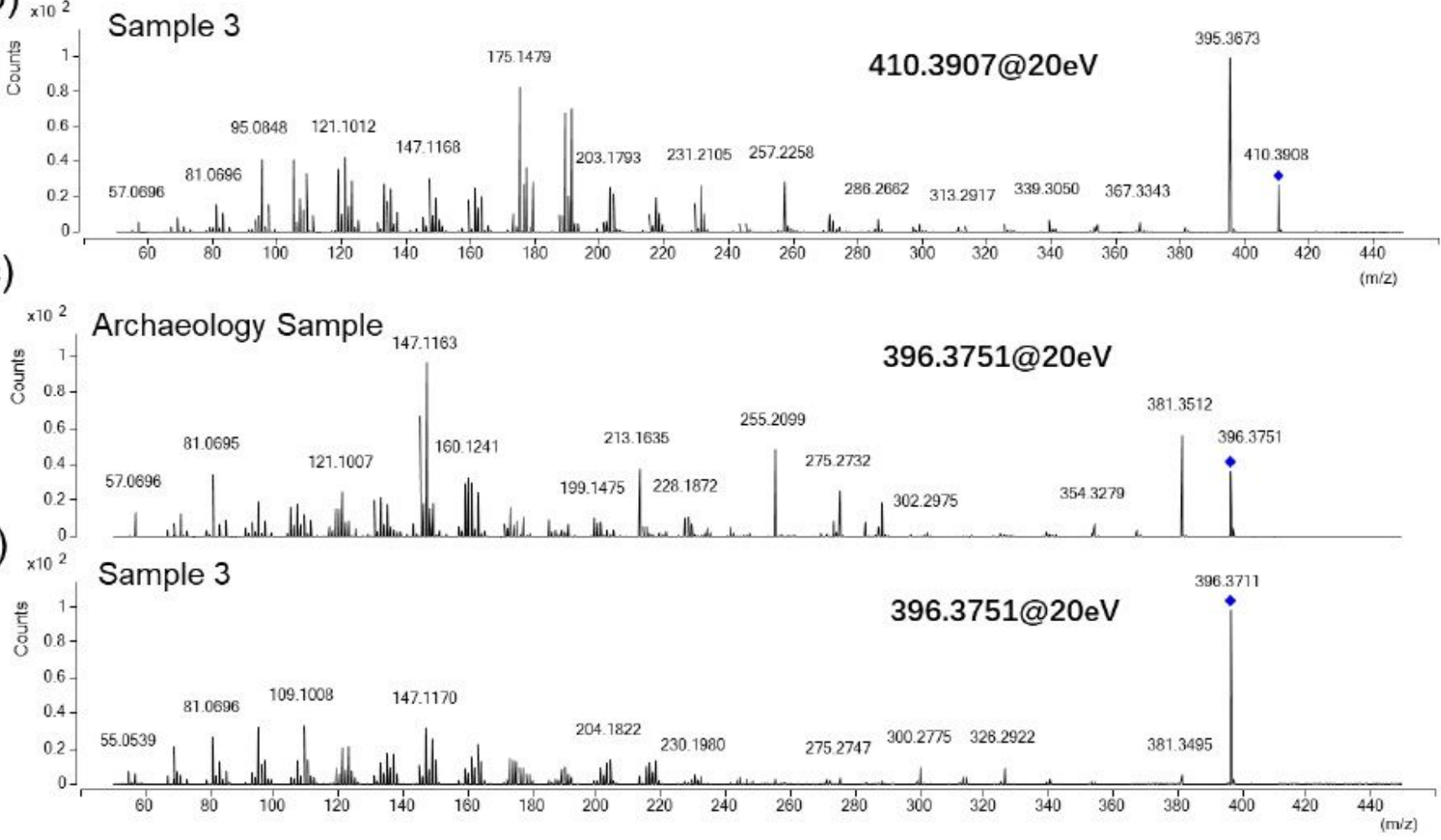

Figure 7

(a), (b) The secondary mass spectrum of ion $\mathrm{m} / \mathrm{z}=410.3907$ extracted in archaeology and sample 3 with the collision energy at $20 \mathrm{eV}$. (c), (d) The secondary mass spectrum of ion $\mathrm{m} / \mathrm{z}=396.3751$ extracted in archaeology and sample 3 with the collision energy at $20 \mathrm{eV}$. 